\title{
An Investigation of Heat Transfer in a Mechanically Agitated Vessel
}

\author{
A. Debab ${ }^{1 \dagger}$, N. Chergui ${ }^{1}$, K. Bekrentchir ${ }^{1}$ and J. Bertrand ${ }^{2}$

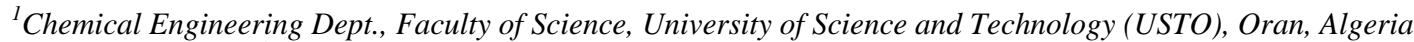 \\ ${ }^{2}$ Chemical Engineering Laboratory, INP-ENSIACET, Toulouse, France \\ $\dagger$ Corresponding Author Email: Abdelkaderdebab@hotmail.com
}

(Received January 8, 2009; accepted May 24, 2010)

\begin{abstract}
The objective of this study is to optimize experimental conditions of agitating a non-Newtonian liquid using experimental design methodology. The measurements of the temperatures have been carried out in a jacketed vessel equipped with Turbine impellers. The rheological properties of aqueous solutions of carboxymethylcellulose sodium salt had been studied using shear stress/shear rate data. The results of the experimental studies, concerning the effect of the diameter of the impeller, the impeller speed and baffled or unbaffled vessel on the overall heat transfer coefficient have been approximated in the form of equations. Based on the optimization criterion, an agitated vessel equipped with Flat Blade Disc Turbine (FBDT) of diameter ratio $\mathrm{d} / \mathrm{D}=0.6$ and baffles is proposed as the most advantageous for heat transfer processes.
\end{abstract}

Keywords: Stirred vessel, Non-Newtonian liquid, Experimental design, Heat transfer coefficient, Wilson plot.

\section{NOMENCLATURE}

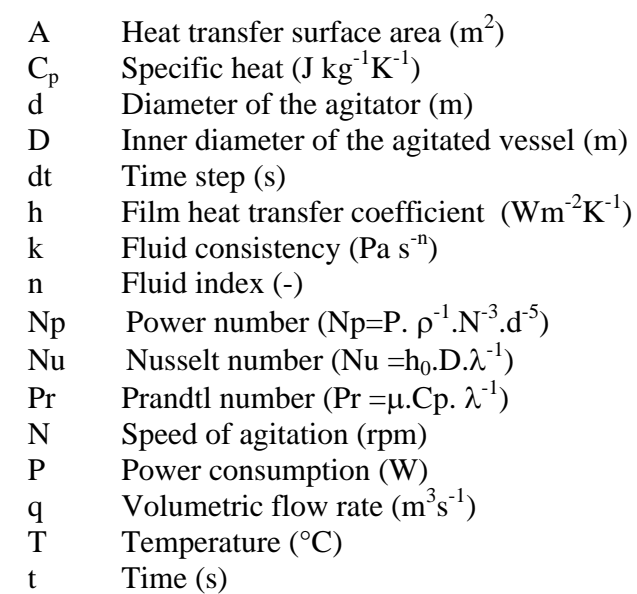

\section{INTRODUCTION}

Mixing has found wide application in chemical and biochemical processing. Many stirred tank bioreactors and chemical reactors require precise control of both mixing and heat transfer to achieve optimum productivity (Oldshue 1983; Harnby et al. 1983; S. Nagata 1975). Heat transfer in agitated vessels is one of the most significant factors for controlling the outcome of biochemical processes. The temperature of fermentation generally must be maintained within very narrow limits (Brian et al. 1989; Yüce et al. 1999). Usually, agitated vessels have a heat transfer surface, in

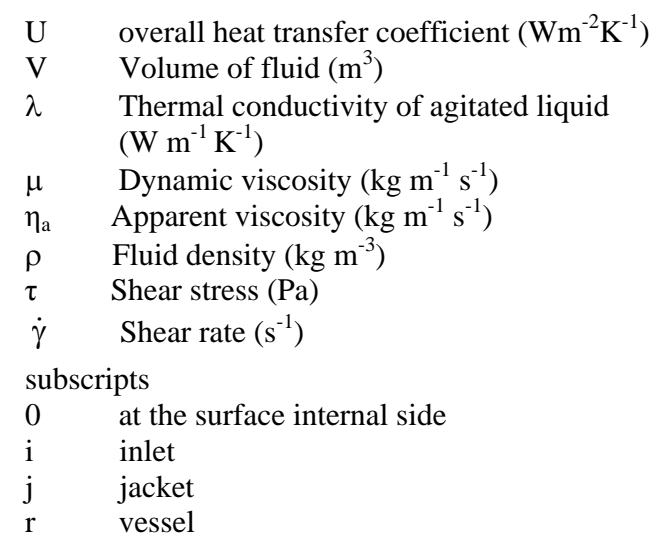

the form of a jacket or internal coils, for addition or removal of the heat.

The intensity of heat transfer during mixing of fluids depends on the type of the agitator, the design of the vessel and conditions of the process. When designing an agitated vessel, the impeller, vessel geometry and baffles should give the degree of mixing the process demands, but it is impractical to specify the agitator to give a specific heat transfer coefficient. The main factor when selecting an agitator is the nature of the fluid. Large diameter agitators operating at low speeds normally give excellent blending and heat transfer characteristics with high viscosity fluids. Small 
impellers operating at high speed are more suited for low viscosity fluids. Turbine impellers are normally used for high speed, low viscosity applications.

The normal design of turbine impeller has either four or six flat blades on a central disc. The ratio of turbine diameter to vessel diameter $d / D$ is usually in the range from $1 / 3$ to $2 / 3$. Baffles are essential in stirred batch vessels to provide good mixing patterns throughout the vessel. They act to reduce tangential flow and promote axial motion. As baffling increases turbulence, it affects the heat transfer rates.

Because heat transfer in agitated vessels is complex, an empirical approach based on dimensionless analysis has been used to predict the average heat transfer coefficients at the jacketed wall. Hence, the results of many heat transfer studies are frequently correlated using a dimensionless equation.

$N u=\theta_{10} \operatorname{Re}^{\theta 20} \operatorname{Pr}^{\theta 30} V i^{\theta 40}$

Where $\theta_{10}, \theta_{20}, \theta_{30}$ and $\theta_{40}$ are found by fitting Eq. (1) to experimental data. A review of many such correlations has been presented by Mohan et al. (1992).

Extensive characterization work has been carried out by authors for different agitator types. The values of the constant $\theta_{10}$ reported are given in Table 1 .

Table 1 Exponent for different impellers and Re regimes

\begin{tabular}{|l|l|l|}
\hline Type of agitator & $\operatorname{Re}$ range & $\theta_{10}$ \\
\hline Flat blade disc turbine & & \\
Unbaffled vessel & $\operatorname{Re}<400$ & 0.54 \\
Baffled vessel & $\operatorname{Re}>400$ & 0.74 \\
\hline $\begin{array}{l}\text { Propeller with three } \\
\text { blades and baffled vessel }\end{array}$ & 5500 to 37000 & 0.64 \\
\hline
\end{tabular}

The typical values for $\theta_{20}, \theta_{30}$ and $\theta_{40}$ are respectively 2/3, 1/3 and 0.14 (Chapman et al. 1965; Strek et al. 1967; Fletcher P. 1987). The constant $\theta_{10}$ which is used to multiply the whole equation have been reported to range from 0.33 to 1.0 , mainly varying due to system geometry and type of impeller.

Attempts were made to study batch heat transfer in an agitated jacketed vessel, with a view to developing a design equation to determine film heat transfer coefficient, $h_{0}$, in such vessels. But as the variables influencing the heat transfer coefficient are quite large in number, complete study covering all the variables could not be made. It is essential to have complete information on the effects of possible variables on the rate of heat transfer and also a general correlation valid over wide ranges of operating conditions for heat transfer coefficients for design and efficient working of the process. The aim of the present work was to study the effect of the impeller speed $\mathrm{N}$, impeller diameter $\mathrm{d}$ and vessel with or without baffles on heat transfer coefficient using an experimental method in which the measurements are mathematically planned.

\subsection{Vessel modeling}

Figure 1 shows the configuration for the agitated vessel used in the experiments.

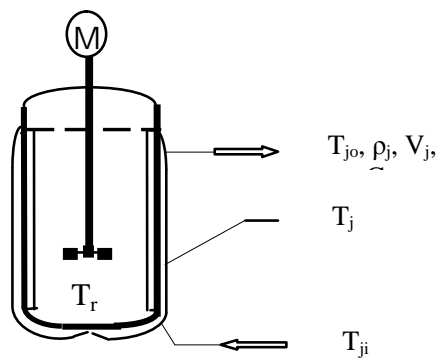

Fig. 1. A typical arrangement of a jacketed vessel with labels.

An energy balance in the vessel, considering the vessel volume and the heat capacity of the vessel contents to be constant, reads:

$\left(\rho_{r} V_{r} C p_{r}\right) \frac{d T_{r}}{d t}=U_{i} A_{i}\left(T_{j o}(t)-T_{r}(t)\right)+\dot{Q}_{s}+\dot{Q}_{r}$

Where $\dot{Q}_{s}$ and $\dot{Q}_{r}$ are the power terms associated with the energy transfer from the stirrer and the heat of reaction, respectively.

On the other hand the energy balance in the jacket can be expressed as:

$\left(\rho_{j} V_{j} C p_{j}\right) \frac{d T_{j}}{d t}=U_{i} A_{i}\left(T_{r}(t)-T_{j o}(t)\right)$
$-\rho_{j} C p_{j} q_{j}\left(T_{j 0}(t)-T_{j i}(t)\right)$

It is assumed that the heat loss of the usually insulated jacket is negligible.

When the test begins, the temperatures in the vessel and in the jacket are respectively $\mathrm{T}_{\mathrm{r}}(0)$ and $\mathrm{T}_{\mathrm{j}}(0)$. Then, the vessel temperature is forced to go up or down when the jacket temperature is changed, suddenly or slowly, to a new set point. The jacket inlet temperature $T_{j i}(t)$ is recorded, and so is the time to go from $\mathrm{T}_{\mathrm{r}}(0)$ to $\mathrm{T}_{\mathrm{r}}(\mathrm{t})$.

With known jacketed surfaces area, flow rates, heat capacities and densities, the time-temperature response is applied to the pertinent mathematical model.

The initial conditions are $T_{j}(t)=T_{j}(0)$ and $T_{r}(t)=T_{r}(0)$. In Eq. (2), since there is no reaction the heat of reaction and kinetic energy transferred from the impeller to the vessel fluid are neglected. Equations (2) and (3) can be rewritten in terms of dimensional groups, as described below. $T_{r}(t)$ is isolated in Eq. (3) as a function of $\mathrm{dT}_{\mathrm{j}} / \mathrm{dt}$, $T_{j 0}(t)$ and $T_{j i}(t)$. The outcome is introduced into Eq. (2) to obtain $d T_{r} / d t$ as a function of the same variables. Then, the obtained equations are differentiated with respect to time and solved by Laplace transform to yield the expression for $T_{r}(t)$ :

$T_{r}(t)=\frac{1}{\beta_{\mathrm{j}}}\left\{\left(\beta_{\mathrm{j}}+\varphi_{j}+\lambda_{1}\right) \cdot C_{1} e^{\lambda_{t} t}-\left(\beta_{j}+\varphi_{j}+\lambda_{2}\right) \cdot C_{2} e^{\lambda_{2} t}\right\}$

Where

$C_{n}=\left\lfloor\lambda_{n} T_{j}(0)+\beta_{j} T_{r}(0)\right\rfloor /\left(\lambda_{1}-\lambda_{2}\right) \quad \mathrm{n}=1,2$

$\lambda_{1}=\frac{1}{2}\left(-z_{1}+\sqrt{z_{1}^{2}-4 z_{2}}\right)$ 


$$
\begin{aligned}
& \lambda_{2}=\frac{1}{2}\left(-z_{1}-\sqrt{z_{1}^{2}-4 z_{2}}\right) \\
& \mathrm{z}_{1}=\beta_{\mathrm{j}}+\phi_{\mathrm{j}} \text { and } z_{2}=\beta_{r} \phi_{j} \\
& \beta_{j}=U_{i} A_{i} /\left(\rho_{j} C p_{j} V_{j}\right) \text { and } \beta_{r}=\left(A_{i} U_{i}\right) /\left(\rho_{r} C p_{r} V_{r}\right) \\
& \phi_{\mathrm{j}}=\mathrm{q}_{\mathrm{j}} / \mathrm{V}_{\mathrm{j}}
\end{aligned}
$$

\subsection{The determination of the Overall Heat Transfer Coefficient}

Overall inside heat transfer coefficient $U_{i}$ is obtained from Eq. (2), it can therefore be rewritten to give:

$U_{i}=\frac{\rho_{r} V_{r} C p_{r}}{A_{i}\left(T_{j 0}(t)-T_{r}(t)\right)} \cdot \frac{d T_{r}}{d t}$

A plot of time versus temperature such as shown in Fig.2 can be used to evaluate $U_{i}$ with sufficient accuracy for design purposes.

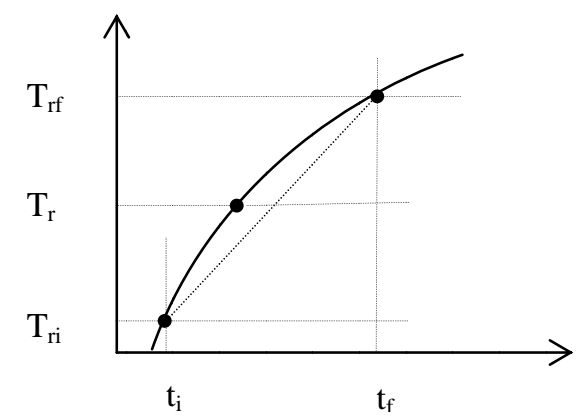

Fig. 2. Temperature plot for unsteady-state heat transfer.

If the time increment $d t$ is evaluated as a specific constant time interval $\Delta \mathrm{t}$, and $T_{r f}$ and $T_{r i}$ are the final and initial temperatures respectively of the liquid being heated, then we can write Eq. (5) as:

$U_{i}=\frac{\rho_{r} V_{r} C p_{r}}{A_{i}\left(T_{j 0}(t)-T_{r}(t)\right)} \cdot \frac{\left(T_{r f}-T_{r i}\right)}{\Delta t}$

Where

$\frac{\left(T_{r f}-T_{r i}\right)}{\Delta t} \sim \frac{d T_{r}}{d t}$

\section{MATERIAL AND MeTHOD}

\subsection{Equipment}

The laboratory equipment is shown in Fig.3; the experiments were conducted in a cylindrical jacketed vessel of 2 liters equipped with a 6-Flat Blade Disc Turbine agitator (6FBDT) as seen in Fig.4. Two agitator diameters were used: $81 \mathrm{~mm}$ and $45 \mathrm{~mm}$, positioned in the vessel at a height from the bottom equal to the half of the height of the liquid medium. The speed of the agitator was varied from $260 \mathrm{rpm}$ to 850 rpm.

The agitated vessel is equipped with a straight jacket, which has a circulating liquid in a closed loop. Heat is provided from this fluid by means of an electric heat exchanger and a thermostatic bath, as indicated in Fig. 3. It is instrumented by four PT-100 temperature sensors; one is positioned in the high part of the agitated fluid $\left(\mathrm{T}_{\mathrm{rh}}\right)$ and the other in the low part $\left(\mathrm{T}_{\mathrm{rb}}\right)$. Water circulate in the jacket and his temperature is measured with two sensors positioned at the inlet $\left(T_{\mathrm{ji}}\right)$ and the outlet side $\left(\mathrm{T}_{\mathrm{jo}}\right)$ of the jacket. Four equallyspaced, flat wall baffles were used each with a width equal to $1 / 10$ of the inner diameter of the vessel.

The Temperature controller controls the jacket temperature and allows tracking a desired set point of the vessel temperature.

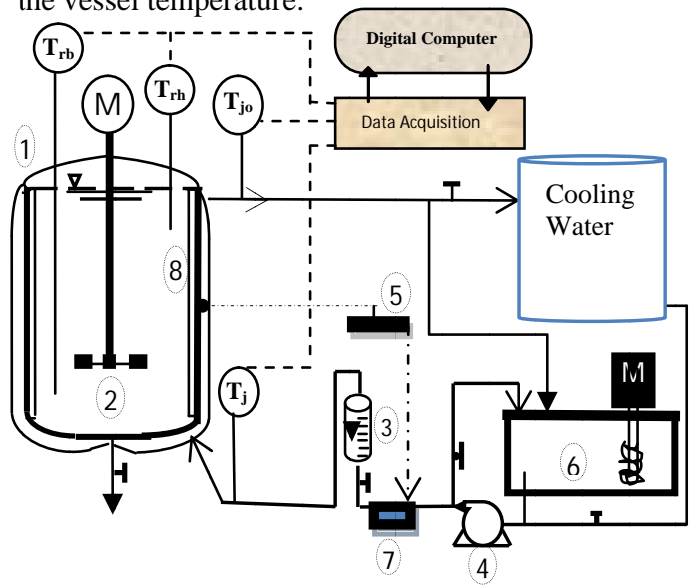

Fig. 3. Schematic representation of the laboratory equipment: 1-Vessel, 2-Agitator, 3-Flow meter, 4-Pump, 5-Temperature controller, 6-Thermostatic bath, 7-Electric heater, 8-Baffles.

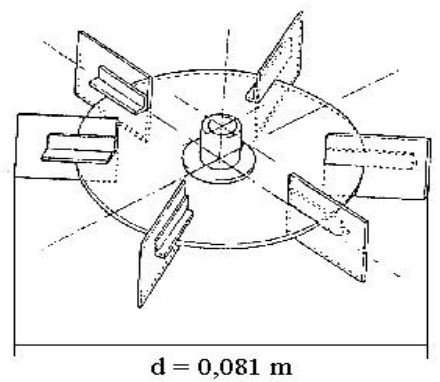

Fig. 4.Agitator used in the investigation

The jacket-side heat transfer coefficient $h_{j}$ depends on the flow of the circulating heat transfer fluid through the jacket; it was calculated for the maximum mass flow rate, which was kept constant during all the experiments according to the correlation given by Werner et al. (1986).

\subsection{Wilson plot method}

The commonly used method to determine the heat transfer coefficient is the Wilson plot method (Wilson 1915). The input data for this method are the physical parameters defining the dimensions of the equipment (the heat transfer surface), the fluids flowing in each circuit, the mass flow rates, and the average temperatures in the inlet and outlet connector pipes. The heat transfer coefficient on each side of the heat transfer surface depends on the flow regime. In order to 
experimentally determine this parameter in given equipment, varied is the mass flow rate in one side, and the mass flow rate in the other side is kept constant. Temperature and mass flow rate are the input parameters varying during the experiment.

The original Wilson plot method was modified in a variety of ways. The modification mainly consisted in changing the number of determined parameters. The original version required knowledge of the exponent at the Reynolds number. Briggs et al. (1969) proposed an iterative method to determine both heat transfer coefficients without knowing of the exponent at the Reynolds number. Further modifications allowed for determining of up to five parameters can be found in Fernandez-Seara et al. (2007).

The overall heat transfer resistance through the wall of the agitated vessel is described by the following approximation formula:

$\frac{1}{U_{i}}=\frac{1}{h_{i}}+R_{w}+\frac{D}{D_{j} h_{j}}$

Where: $R_{w}$ is the wall resistance. It should be noticed that every liquid can produce a layer or deposit of extraneous materials on the heat transfer surface, which will provoke a time-modification of both film heat transfer coefficients. In these cases, the heat transfer resistance increases considerably due to the fact that this type of materials normally has a lower thermal conductivity. This effect is referred to as the fouling or dirt factor, and should be avoided or, if this is not possible, taken into account as a further resistance to heat transfer.

Substituting to Eq. (1) definitions of the similarity numbers, the heat transfer coefficient $h_{i}$ can be expressed in the form:

$h_{i}=\alpha_{0} \cdot N^{\theta_{20}}$

Where, $\alpha_{0}$ is a constant.

According to Eq. (8), only the stirrer speed can modify the value of the internal film heat transfer coefficient for a given vessel, with the same liquid and temperature conditions inside it. The value of $\alpha_{0}$ is described by Eq. (9).

$\alpha_{0}=\theta_{10} \frac{\lambda}{D} \operatorname{Pr}^{\theta_{30}} \operatorname{Vi}^{\theta_{40}}\left[\frac{\mathrm{d}^{2} \cdot \rho}{\mu}\right]^{\theta_{20}}$

Where $\theta_{10}, \theta_{20}, \theta_{30}, \theta_{40}$ are constant for every system.

Substituting Eq. (8) to Eq. (7) we arrive at the following equation, used in the calculations:

$\frac{1}{U_{i}}=\frac{1}{\alpha_{0}} N^{-\theta_{20}}+R_{w}+\frac{D}{D_{j} h_{j}}$

When the power generated in the vessel is small, the viscosity number $(V i)$ can be neglected, if temperature difference between the wall of the vessel and the fluid temperature is not so large.
Assuming that $\alpha_{0}$ has a constant value under the conditions previously mentioned, it is possible to determine experimentally the value of $h_{i}$, using the Wilson plot.

Substituting the new variables:

$y=\frac{1}{U_{i}}$

$x=N^{-\theta_{20}}$

$a=\frac{1}{\alpha_{0}}$

$b=R_{w}+\frac{D}{D_{j} h_{j}}$

Equation (10) can be linearized:

$y=a \cdot x+b$

A straight line can be plotted in Fig. 5 using Eq. (15).

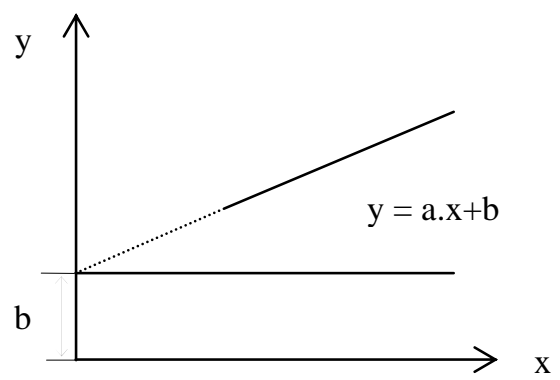

Fig. 5. Original Wilson plot for $h_{i}$ experimental determination

The slope of the straight line is the reciprocal of $\alpha_{0}$. When the stirrer speed has no effects on the value of $h_{i}$ $(\mathrm{N} \rightarrow \infty), 1 / \mathrm{U}$ gives the parameter $\mathrm{b}$.

\subsection{Planned experimental method}

The influence of different geometrical parameters of the agitated vessel on the heat transfer coefficient can be determined using experimental method in which the measurements are mathematically planned (Goupy 1996). As detected in previous study (Chergui 2005) the most influential factors on the heat transfer coefficient are the impeller diameter $\left(\mathrm{X}_{1}\right)$, the baffles $\left(\mathrm{X}_{2}\right)$ and the impeller speed $\left(\mathrm{X}_{3}\right)$. In order to evaluate the effects and interactions of these three factors, a $2^{3}$ factorial design is used. The experimental conditions required by this design are defined in Table 2 .

Table 2 Levels of the factors

\begin{tabular}{|c|c|c|c|}
\hline & $\begin{array}{c}\mathbf{d}(\mathbf{m}) \\
\mathbf{X}_{\mathbf{1}}\end{array}$ & $\begin{array}{c}\text { Baffles } \\
\mathbf{X}_{\mathbf{2}}\end{array}$ & $\begin{array}{c}\mathbf{N}(\mathbf{r p m}) \\
\mathbf{X}_{\mathbf{3}}\end{array}$ \\
\hline Level + & 0.081 & $\begin{array}{c}\text { With } \\
\text { baffles }\end{array}$ & 850 \\
\hline Level - & 0.045 & $\begin{array}{c}\text { Without } \\
\text { baffles }\end{array}$ & 260 \\
\hline
\end{tabular}

The levels chosen for each of the three parameters are also presented in this table, e.g., a low level is transformed to the number -1 and a high level to the number +1 . 
The mathematical model associated with this type of planned experiments is a linear regression which takes into account the effects of the factors as well as the effects of their interactions.

It is written as:

$$
\begin{aligned}
& Y=b_{0}+b_{1} X_{1}+b_{2} X_{2}+b_{3} X_{3}+b_{12} X_{1} X_{2}+ \\
& b_{13} X_{1} X_{3}+b_{23} X_{2} X_{3}+b_{123} X_{1} X_{2} X_{3}
\end{aligned}
$$

Where $Y$ represents the estimated response, it represents the overall heat transfer coefficient $h_{i}$ and $\mathrm{X}_{\mathrm{i}}$ are independent variables in code. The constant $b_{0}$, is the average experimental response, the coefficients $b_{1}, b_{2}$ and $b_{3}$ are the estimated effects of the factors considered and the extent to which these terms affect the performance of the method is called main effect. The coefficients $b_{12}, b_{13}, b_{23}$ and $b_{123}$ are called the interaction terms. The coefficients $b_{i j}$ of the model are estimated from experimental responses. Following the model fitted for each response, we represent graphically isoresponses surfaces which are three-dimensional models of the relationship between the responses and two factors. This response surfaces methodology allows experimental responses behavior to be described as precisely as possible as a function of factor variation and optimal conditions of the factors to be determined for each experimental response. We can see from Eq. (16) that the factorial design provides information about the importance of interactions between the factors. This means that sometimes the level in which some factors must be set is influenced by their interaction with others, so that we can ensure a better expected experimental response.

The statistical significance of each term, in Eq. (16), was verified using the t-Student.

\section{RESULTS AND DISCUSSION}

\subsection{Rheological Behavior of Aqueous Solution of Carboxymethyl Cellulose Sodium Salt}

A $2 \%$ dilute concentration of aqueous polymer solution of sodium carboxymethyl cellulose sodium salt (CMC) was chosen as a test fluid. To study the effect of temperature on rheology, the measurements were carried out at temperatures between $30^{\circ} \mathrm{C}$ to $60^{\circ} \mathrm{C}$ and shear rates ranging between $6.45 \mathrm{~S}^{-1}$ to $645 \mathrm{~S}^{-1}$. The experimental set up to perform these experiments were a variable speed, coaxial cylinder thermostated rheometer (VT550). A plot of the flow curves, shear stress versus shear rate at four different temperatures are shown in Fig. 6.

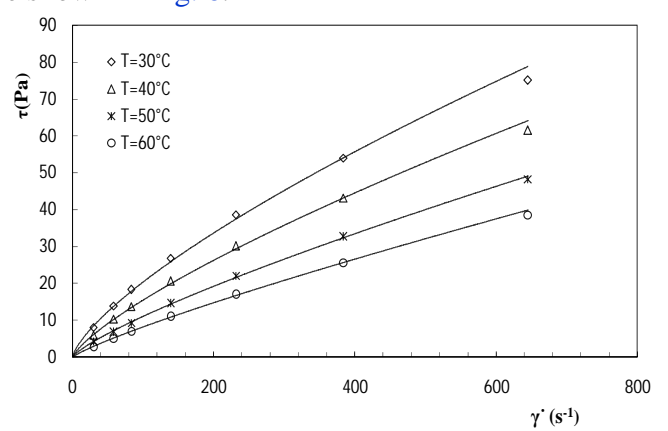

Fig. 6. The dependence of shear stress on the shear rate.
We observed that the experimented fluid exhibits a rheofluidifiant behavior governed by the Ostwald de Waele power-law model:

$\tau=k \cdot \dot{\gamma}^{n}$

Where $\mathrm{k}$ is the consistence index and $\mathrm{n}$, is the flow behavior index.

Table 3 provides some sample numerical values of $\mathrm{k}$ and $\mathrm{n}$.

Table 3 Values of the index of flow and consistency for various values of temperatures

\begin{tabular}{|c|c|c|}
\hline \multirow{2}{*}{ T, ${ }^{\circ} \mathbf{C}$} & \multicolumn{2}{|c|}{ 2\% C.M.C } \\
\cline { 2 - 3 } & $\mathrm{N}$ & $\mathrm{k}, \mathrm{Pa}^{\mathrm{n}}{ }^{\mathrm{n}}$ \\
\hline 30 & 0.7272 & 0.7142 \\
\hline 40 & 0.761 & 0.4661 \\
\hline 50 & 0.8153 & 0.2544 \\
\hline 60 & 0.8483 & 0.1646 \\
\hline
\end{tabular}

The consistency index, $\mathrm{k}$, decreases with increasing temperature $T$. It is correlated with temperature as follows:

$k=a \cdot e^{b T}$

Where $a$ and $b$ are constants.

The fluid behavior index, $\mathrm{n}$, showed no noticeable variation with temperature change.

In Fig. 7 we could observe the influence of the temperature on the apparent viscosity. A decrease in viscosity was produced when the temperature increases.

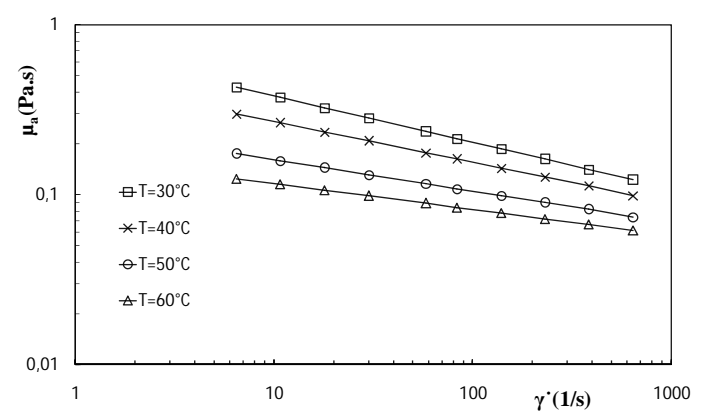

Fig. 7. The dependence of apparent viscosity on the shear rate.

The apparent viscosity is computed from the following equation:

$\eta_{a}=k \dot{\gamma}^{n-1}$

\subsection{Influence of Non-Newtonian Flow Behavior on Mixing Process Characteristics}

In an agitated vessel, the rheological properties of the material to be processed are of main importance regarding the parameters which have to be considered for the configuration. The viscosity influences the formation of the flow field inside the tank and, therefore, the mixing and power behavior. 
Thus, the viscosity is the most important characteristic value. While Newtonian fluids are characterized by a constant viscosity, the processing of non-Newtonian materials demands the consideration of a changing viscosity through a viscosity function.

For the configuration of agitators for the processing of non-Newtonian materials, the changing viscosity needs to be considered, where the Reynolds number is the decisive characteristic value. The main problem is the determination of the correct viscosity at a set rotation rate; as a consequence the Reynolds number cannot be calculated. This means that also the mixing time and power characteristics only can be included as approximations in the configuration stage. For this reason, several methods, which enabled the construction of a stirring apparatus for the processing of non-Newtonian fluids by relating speed and viscosity to each other, were developed in the past. For power law fluids, a linear correlation between rotation rate of the stirrer and mean shear rate $\overline{\dot{\gamma}}$ in the agitated vessel can be described by a linear correlation according to the method of Metzner and Otto (1957).

$\overline{\dot{\gamma}}=\mathrm{K}_{\mathrm{s}} \mathrm{N}$

Where the constant $\mathrm{K}_{\mathrm{s}}$ in pseudo-plastic fluids has the value 11.5 , when a flat blade disc turbine is used; for the pitched blade turbine $\left(\theta=45^{\circ}\right)$ the value is 13 and for the propeller it is 10 (Reinhold et al. 1980).

\subsection{Heat Transfer Calculation}

\subsubsection{Experimental Determination of Heat Transfer Coefficients by Wilson Plot}

A computer programme was used to analyze the data taken from the experiments in this heat transfer study. The first step of the calculation deals with the estimation of an averaged Overall heat transfer coefficient $U_{i}$ from Eq. (6) and the experimental timetemperature results presented in Fig. 8

The values calculated from Eq. (6) are presented in Table 4.

Table 4 Values of N, Re and $U_{i}$

\begin{tabular}{|c|c|c|c|c|}
\hline \multicolumn{2}{|l|}{ FBDT $(\mathrm{d}=81 \mathrm{~mm})$} & \multicolumn{2}{l|}{ FBDT $(\mathrm{d}=45 \mathrm{~mm})$} \\
\hline $\mathrm{N}(\mathrm{rpm})$ & $\operatorname{Re}$ & $\mathrm{U}_{\mathrm{i}}$ & $\operatorname{Re}$ & $\mathrm{U}_{\mathrm{i}}$ \\
\hline 260 & 142.80 & 129.30 & 140.78 & 83.95 \\
\hline 450 & 241.95 & 188.68 & 265.07 & 116.22 \\
\hline 650 & 353.75 & 240.82 & 373.49 & 146.68 \\
\hline 850 & 430.91 & 276.19 & 573.08 & 189.72 \\
\hline
\end{tabular}

From Table 4, it can be seen that the heat transfer coefficient is calculated in the transition regime.

In the second part of the steady, the time response of the theoretical vessel temperature $\mathrm{T}_{\mathrm{v}}(\mathrm{t})$ using Eq. (4) is presented in Fig. 8. From these plots it could be clearly seen that the agreement between the experimental data and the theoretical values calculated using Eq. (4) is satisfactory. Similar plots prepared for the agitator of $45 \mathrm{~mm}$ diameter also indicated satisfactory agreement.

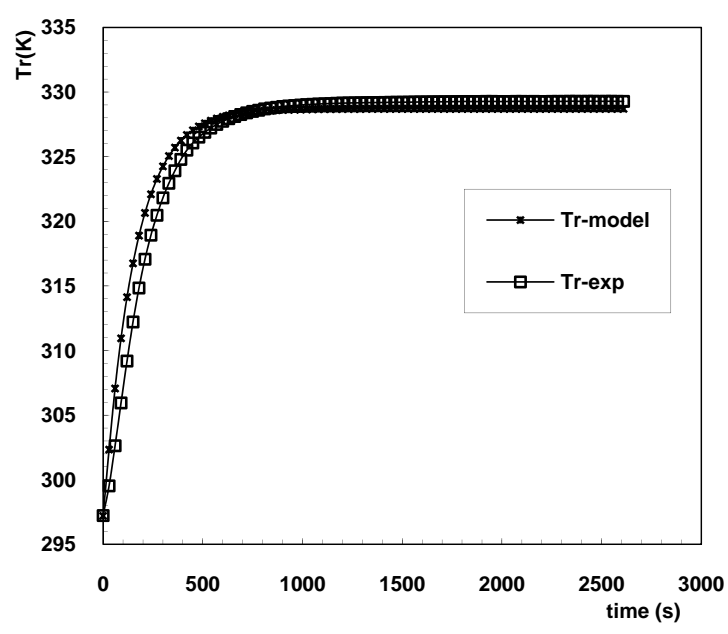

Fig. 8. Time-Temperature Plots for FBDT $\mathrm{d}=81 \mathrm{~mm}$ and $\mathrm{N}=850 \mathrm{rpm}$.

The third step deals with the determination of the partial heat transfer coefficient $h_{i}$ using Wilson plot method.

The calculated values of the local heat transfer coefficient $h_{i}$ from the Wilson graphs have been plotted against the speed of the impeller for each of the impellers. From this plots it has been deducted the correlations given in Table 5 .

Table 5 Values of $h_{i}$

\begin{tabular}{|c|c|}
\hline FBDT $(\mathrm{d}=81 \mathrm{~mm})$ & FBDT $(\mathrm{d}=45 \mathrm{~mm})$ \\
\hline $\mathrm{h}_{\mathrm{i}}=3.697 \mathrm{~N}^{2 / 3}$ & $\mathrm{~h}_{\mathrm{i}}=2.158 \mathrm{~N}^{2 / 3}$ \\
\hline
\end{tabular}

\subsubsection{Prediction of the Film Heat Transfer Coefficient by the Planned Experimental Method}

The mathematical model derived from the experimental results is presented by the following equation:

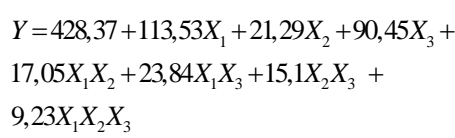

A second test was done in order to check the test of Fischer (Goupy 1996), this test shows that the mathematical model is representative. To be able to represent graphically this equation; it is necessary to stay constant one of the parameters, for example the baffles referred by the parameter $\left(\mathrm{X}_{2},\right)$, then we obtain the following equations:

For $\mathrm{X}_{2}=+1$ (vessel with baffles)

$$
\begin{aligned}
& Y=449.66+130.58 X_{1}+105.55 X_{3}+ \\
& 33.07 X_{1} X_{3}
\end{aligned}
$$


For $\mathrm{X}_{2}=-1$ (vessel without baffles)

$Y=407.06+96.48 X_{1}+75.35 X_{3}+$
$14.61 X_{1} X_{3}$

The mathematical models described by Eq. 22 and Eq. 23, reported as response surface contours in Fig. 9 and Fig. 10 respectively. We note that two factors have more weight than the third, which is the impeller speed $\mathrm{X}_{3}$ and the diameter of the agitator $\mathrm{X}_{1}$. The film heat transfer coefficient $h_{i}$ (represented by $Y$ ) increases when the diameter of the agitator increases from $0.045 \mathrm{~m}$ to $0.081 \mathrm{~m}$, this is due to flow pattern and the circulation loops generated by each impeller.

The applicability of the models for the prediction of the overall heat transfer coefficient in the agitated vessel used in this study is demonstrated in Fig. 11, where all experimental data obtained for various operating conditions are compared with those predicted from Eq. (6).

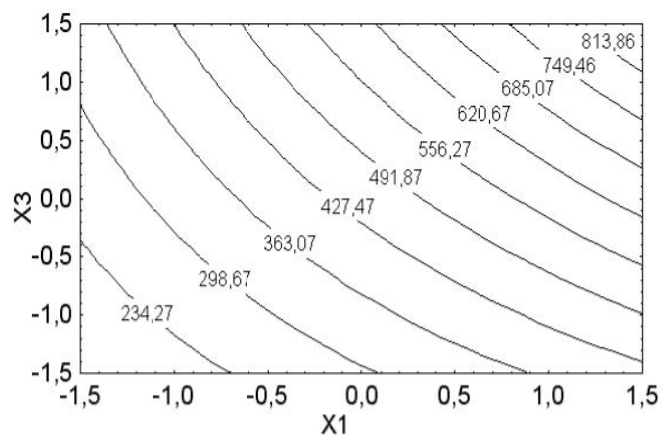

Fig. 9. Response surface contours for $X_{2}=-1$.

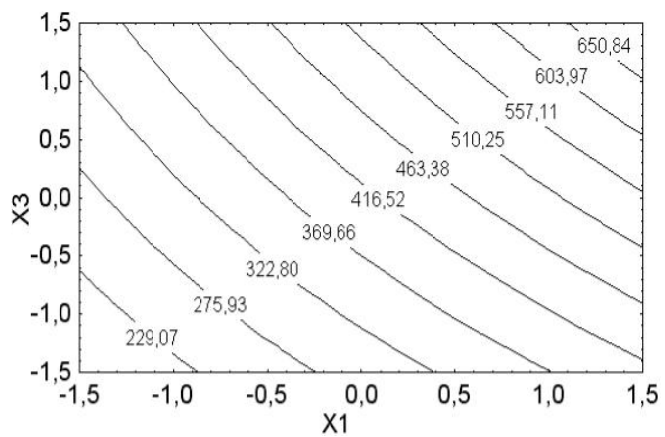

Fig. 10. Response surface contours for $X_{2}=+1$.

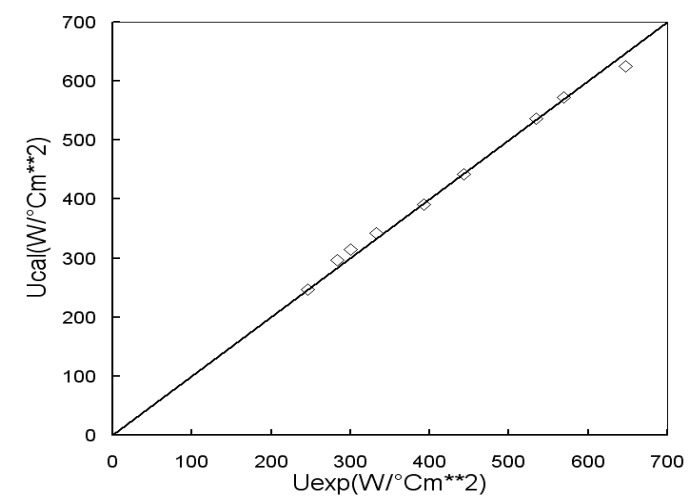

Fig. 11. Comparison of the experimental values and those calculated from Eq. (22).

\section{CONCLUSION}

In this work, experimental design methodology has been used in order to determine the effects of the impeller diameter, the speed of the impeller and the baffles on the overall heat transfer coefficient in a mechanically stirred tank equipped with a jacket. Response surface contours methodology allowed the optimal parameters to be determined. The film heat transfer coefficient is strongly dependent on the speed of the impeller so that it is proportional to $\mathrm{N}^{2 / 3}$.

The rheological characterization of the aqueous solution of CMC employed in this study allows concluding that the concentration of $2 \%$ mass represent a nonNewtonian behavior in the range of shear rates studied. The fluid behavior index, $\mathrm{n}$, showed no noticeable variation with temperature change but the consistency index, $\mathrm{k}$, decreases with increasing temperature.

The present analysis demonstrated the feasibility to use the Wilson method to predict the heat transfer coefficient in an agitated vessel. The experimental and the calculated values of the mean overall heat transfer coefficient compare favorably.

\section{REFERENCES}

Brain, T.J.S. and L. Man (1989). Heat transfer in stirred tank bioreactors, Chem. Eng. Progress, 76-80.

Briggs, D.E. and H. Young (1969). Modified Wilson plot techniques for obtaining heat transfer correlations for shell and tube heat exchangers, Chemical Engineering Progress Symposium Series, 92(65), 35-45.

Chapman, F.S. and F. Holland (1965, January). Heat transfer correlations for agitated liquids in process vessels, Chemical Engineering, 18, 153-158.

Chergui, N. (2005). Modeling Heat Transfer in Agitated Vessel. Master thesis, University of Science and Technology of Oran (USTO), Algeria.

Debab, A. (2002). Effects of Mixing on Heat Transfer in Jacketed Vessel. Ph.D. thesis. National Polytechnic Institute (ENSIACET), Toulouse, France.

Fernandez-Seara, J., J. Uhia, J. Sieres and A. Campo (2007). A general review of the Wilson plot method and its modifications to determine convection coefficients in heat exchange devices, Applied Thermal Engineering, 27, 2745-2757.

Fletcher, P. (1987). Heat transfer coefficients for stirred batch reactor design, The Chemical Engineering, 33-37.

Goupy, J. (1996). La Méthode des Plans d'Expériences. Ed. Dunod, Paris.

Harnby, N., F. Edwards and A. Nienow (1985). Mixing in the Process Industries. Butterworth's, London.

Metzner, A., and R. Otto (1957). Agitation of nonNewtonian fluids, AIChE Journal 3(1), 3-11. 
A. Debab et al. / JAFM, Vol. 4, No. 2, Issue 1, pp. 43-50, 2011.

Mohan, P., A. Nicholas and T. Al-Hassan (1992). Heat transfer to Newtonian fluids in mechanically agitated vessels, Experimental Thermal and Fluid Science 5, 861-883.

Nagata, S. (1975). Mixing, Principles and Applications. Halsted, New York.

Oldshue, J.Y. (1983). Fluid Mixing Technology. McGraw-Hill, New York.

Reinhold, P., S. Artur and W. Paul-Michael (1980). Heat transfer in agitated vessels with single-phase liquids, German Chemical Engineering Journal 3, 163-174.

Strek, F. and S. Masiuk (1967). Heat transfer in liquid mixers, International Chemical Engineering 7(4), 693-702.

Yüce, S., A. Hasaltun, S. Erdogan and M. Alpbaz (1999). Temperature control of a batch polymerization reactor, International Chemical Engineering 77(A), 413-420.

Werner, A. and W. Schmidt (1986). Heat transfer in agitated tank with liquid media, German Chemical Engineering Journal 9, 362-37.

Wilson E.E. (1915). A basis of rational design of heat transfer apparatus, ASME Journal of Heat Transfer $37,47-70$ 